\title{
Evaluation of Multiple Satellite-Based Precipitation Products for the Rainfall- Runoff Simulation over a Typical Catchment of Southwest China
}

\author{
Shilei CHEN ${ }^{\mathrm{a}, \mathrm{b}, \mathrm{l}}$, Qiang WANG ${ }^{\mathrm{a}, \mathrm{b}}$, Hengfei ZHANG ${ }^{\mathrm{a}, \mathrm{b}, \mathrm{c}}$, Changwen LI $^{\mathrm{b}}$ and Ling \\ $\mathrm{ZENG}^{\mathrm{d}}$ \\ ${ }^{a}$ Changjiang Schinta Software Technology Co., Ltd, Wuhan 430010, China \\ ${ }^{\mathrm{b}}$ Changjiang Institute of Survey, Planning, Design and Research, Wuhan 430010, \\ China \\ ${ }^{\mathrm{c}}$ National Dam Safety Engineering and Technology Research Center, Wuhan 430010, \\ China \\ ${ }^{\mathrm{d}}$ Changjiang Bureau of Hydrology, Wuhan 430010, China
}

\begin{abstract}
Five non-real time satellite-based precipitation products (SPPs), including TMPA 3B42V7, CMORPH CRT, PERSIANN-CDR, GSMaP_MVK and GSMaP_Gauge, were evaluated over the Xijiang Basin. By driving XAJ model with each of the SPPs and gauge-based interpolation precipitation data to compare the hydrological responses at Wuzhou Station during the period of 2010-2017, this study also evaluated the applicability of these SPPs in rainfall-runoff simulation over the Xijaing Basin. The results showed that: (1) GSMaP_Gauge had highest accuracy, then are CMORPH CRT and TMPA 3B42V7, respectively, and finally are PERSIANN-CDR and GSMaP_MVK; (2) Among the five SPPs, CMORPH CRT, GSMaP_Gauge and TMPA-3B42 V7 have comparable performance in rainfall-runoff simulation, with NSE value lower than that generated by driving gauge-based interpolation precipitation and obviously higher than that of PERSIANN-CDR, and the uncorrected SPP, i.e., GSMaP_MVK, performs worst because of large systematic errors.
\end{abstract}

Keywords. Multiple satellite-based precipitation products, rainfall-runoff simulation, hydrological response, Xijiang Basin

\section{Introduction}

As the basic driven element of hydrological process, precipitation is the most principal input effecting the simulation performance of hydrological model [1]. Many researches have shown that precipitation data of high temporal and spatial resolution, high-precision plays an important role in the calibration of hydrological characteristic parameters and the simulation of hydrological processes such as surface runoff, soil evaporation,

${ }^{1}$ Corresponding Author, Shilei CHEN, Changjiang Schinta Software Technology Co., Ltd, Wuhan 430010, China; Email: chenslwater@126.com.

Other Authors’ Emails: wangqiang@cjwsjy.com.cn; zhanghengfei@cjwsjy.com.cn; lichangwen@cjwsjy.com.cn; zengling128@hotmail.com. 
vegetation transpiration, and soil moisture change.

Traditionally, the precipitation input of rainfall-runoff models is derived from the rain gauge observations. However, the quality of this kind of data is limited by the strong spatiotemporal variability of precipitation, the topography effect, and the non-typical distribution of the rain gauges stations. When the gauge stations are with low density or unevenly distributed, the interpolation data cannot represent the real spatial distribution of precipitation [2-5]. In recent years, the development of satellite remote sensing technology has brought a new opportunity for the spatial precipitation estimates. Series of SPPs has been successfully developed based on the rain radar, microwave and infrared observation technologies. The high spatio-temporal resolution, wide coverage and low cost makes SPPs attractive in the rainfall-runoff simulation, especially for areas with complex terrain/climate conditions and sparse rain gauge network density.

Currently, the mainstream SPPs consists of five series, i.e., TMPA (TRMM Multisatellite Precipitation Analysis) series [6], CMORPH (CPC Morphing technique) series [7], PERSIANN (Precipitation Estimation from Remotely Sensed Information using Artificial Neural Networks) series [8], GSMaP (Global Satellite Mapping of Precipitation) series [9] and IMERG (Integrated MultisatellitE Retrievals for Global Precipitation Measurement) series [10]. Each of the series contains near real time products and non-real time post processing products. Benefiting from more data source involved in the retrieval algorithm, non-real time products generally have higher estimation accuracy in comparison to near real time products. This paper evaluates the applicability of fivenon-real time SPPs with long time series data (i.e., TMPA 3B42V7, CMORPH CRT, PERSIANN-CDR, GSMaP_MVK and GSMaP guage) in rainfallrunoff simulation over the Xijaing Basin.

\section{Study Area and Data Preparation}

\subsection{Study Area}

The Xijiang Basin covers $353,100 \mathrm{~km}^{2}$ area, accounting for $77.8 \%$ of the total area of the Pearl River Basin [11]. It has sub-tropical and tropical monsoon climates, with annual average runoff amount, precipitation and temperature of 230 billion $\mathrm{m}^{3}, 1200-1900 \mathrm{~mm}$ and $14-22{ }^{\circ} \mathrm{C}$, respectively. Flood events in this basin are mainly formed by heavy rainstorms, so the occurrence time of flood events keeps consistent with the heavy rainstorm time, which are usually found from April to September. In this paper, the Xijaing Basin up to Wuzhou Station, accounting for $93.4 \%$ of the total area of the Xijiang Basin, is selected as the study area (as shown in figure 1).

\subsection{Satellite-Based Precipitation Products (SPPs)}

\subsubsection{TMPA $3 B 42 V 7$}

TMPA series are generated by the TRMM Science data and Information System of NASA based on TRMM Multi-satellite Precipitation Analysis. The near real time data, i.e., TMPA 3B42RT, is released 9 hours after the precipitation event; and the non-real time data, i.e., TMPA 3B42V7, generated by correcting TMPA 3B42RT with GPCC monthly precipitation data, is released during the 10-15th days of the next month (i.e., delaying about 10-46 days). 


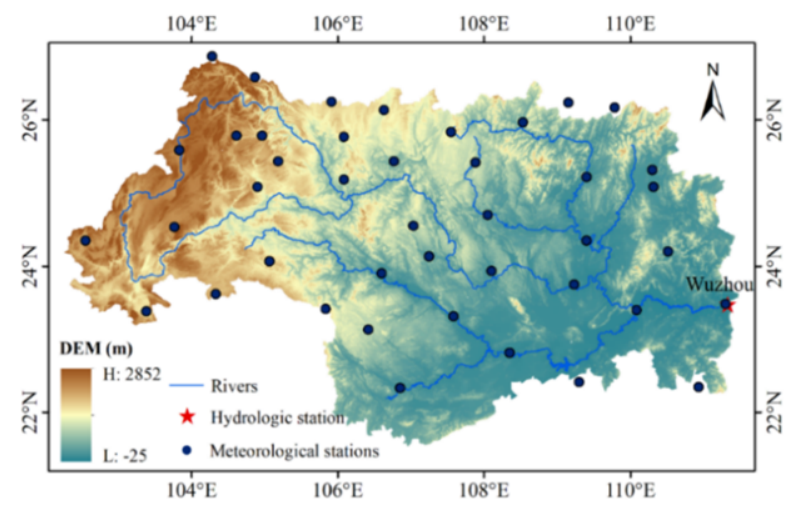

Figure 1. Overview of study area.

The precipitation data of TMPA series covers the areas of $50^{\circ} \mathrm{N} \sim 50^{\circ} \mathrm{S}$, with spatial resolution of $0.25^{\circ} \times 0.25^{\circ}$ and temporal resolution of three hours, one day, one month and other scales. Each TMPA version can be found at NASA's tropical precipitation observation website (https://trmm.gsfc.nasa.gov) for free. In this paper, TMPA 3B42V7 data with temporal resolution of three hours is accumulated to daily scale for rainfall runoff simulation.

\subsubsection{CMORPH CRT}

CMORPH series are developed by the Climate Prediction Center (CPC) of National Oceanic and Atmospheric Administration (NOAA) based on Morphing algorithm. By correcting the near real time data (i.e., CMORPH) with CPC and GPCP monthly precipitation data, non-real time post processing data CMORPH CRT is generated. CMORPH series products have two kinds of temporal and spatial resolutions: one with temporal resolution of $30 \mathrm{~min}$ and spatial resolution of $8 \mathrm{~km} \times 8 \mathrm{~km}$ and another one with temporal resolution of 3 hours and spatial resolution of $0.25^{\circ} \times 0.25^{\circ}$. These two kinds of data could be downloaded freely from the CMORPH data server of CPC (ftp://ftp.cpc.ncep.noaa.gov/precip/global_CMORPH/). In this paper, the latter one, i.e., CMORPH CRT data with temporal resolution of three hours and spatial resolution of $0.25^{\circ} \times 0.25^{\circ}$, is preferred as there are often missed data in the first one and accumulated to daily scale for rainfall runoff simulation.

\subsubsection{PERSIANN-CDR}

PERSIANN series are developed by Center for Hydrometeorology and Remote Sensing (CHRS), University of California, Irvine based on Artificial Neural Network (ANN) Model. In comparison to CMORPH, PERSIANN uses infrared data in a way more directly. Near real time data PERSIANN is inversed by ANN model and after correction by monthly precipitation data (resolution of $2.5^{\circ} \times 2.5^{\circ}$ ) from GPCP, non-real time post processing data PERSIANN-CDR (PERSIANN-Climate Data Record) is generated. These two kinds of data, covering the earth's areas of $60^{\circ} \mathrm{N} \sim 60^{\circ} \mathrm{S}$ with spatial resolution of $0.25^{\circ} \times 0.25^{\circ}$, could be downloaded through the official website of CHRS (https://chrsdata.eng.uci.edu/). The highest spatial resolution of PERSIANN-CDR is one day and the lag time is relatively big due to the deviation correction based on GPCP monthly precipitation data. In this paper, PERSIANN-CDR data with temporal resolution of one day is selected for rainfall-runoff simulation. 


\subsubsection{GSMaP_MVK and GSMaP_Gauge}

GSMaP, a global SPP series with high spatiotemporal resolution, is developed by JAXA based on Kalman filtering model. There are two kinds of products in the GSMaP series: near real time data GSMaP_NRT and non-real time post processing data GSMaP_MVK and GSMaP_Gauge. GSMaP NRT is obtained by using forward-only cloud advection vector for the fusion of microwave and infrared data, while GSMaP_MVK is obtained by using bidirectional cloud advection vector for the fusion of microwave and infrared data. And after the deviation correction on GSMaP_MVK, GSMaP_Gauge is obtained. The release time of GSMaP_NRT is four hours late after the precipitation while the GSMaP_MVK and GSMaP_Gauge for three days. Data of the GSMaP series could all be downloaded on JAXA's GSMaP data server (ftp://rainmap:Niskur+1404@hokusai.eorc.jaxa.jp/) for free. In this paper, GSMaP_MVK and GSMaP_Gauge data with temporal resolution of one hour is accumulated to daily scale for rainfall runoff simulation.

\subsection{Rain Gauge Data}

The rain gauge data used in this study refers to the daily observations of 42 rain gauges, which are downloaded from China Meteorological Data Network (http://data.cma.cn). The daily observations at 42 rain gauge sites are interpolated with the inverse distance weighted averaging (IDW) method to obtain the areal rain observation data.

\subsection{Other Hydro-Meteorological Data}

The hydro-meteorological data required to drive XAJ model include the discharge data of catchment outlet, the areal precipitation data and the areal reference crop potential evapotranspiration. The outlet discharge data used in this study refers to the observed daily streamflow at Wuzhou Station from January 1, 2010 to December 31, 2017. In terms of the meteorological data, daily wind speed, relative humidity, minimum temperature, maximum temperature, and sunshine duration of 42 stations are downloaded and used for the computation of reference crop potential evapotranspiration $(P E T)$ with the FAO-56 Penman-Monteith method [12]. By interpolating the computed $P E T$ of 42 stations with the IDW method, the areal PET are obtained to drive the XAJ model.

\section{Methodology}

\subsection{XAJ Model}

The XAJ model initially developed by Zhao et al. [13] is a widely used lumped rainfallrunoff model for flood forecasting in China. Based on saturation excess mechanism, this model is especially applicable for humid and semi-humid areas.

It contains four calculation procedures, namely evapotranspiration, runoff generation, runoff partition and runoff concentration. In order to compute evapotranspiration more truly, the XAJ model used in this study divides soil into three layers, i.e., upper layer, lower layer and deep layer, which refer to the thin topsoil where evaporation mainly occurs, the soil where vegetation roots dominate, and the soil 
comprising deep roots of vegetation, respectively. There will be different runoff components generated in these three soil layers, namely surface runoff, inter runoff and groundwater runoff, and the soil water change in each layer results from evapotranspiration and runoff. Then, the surface runoff is routed by the unit hydrograph method, while the inter runoff and the ground runoff are routed by the linear reservoir method. The model structure can be found in figure 2 .

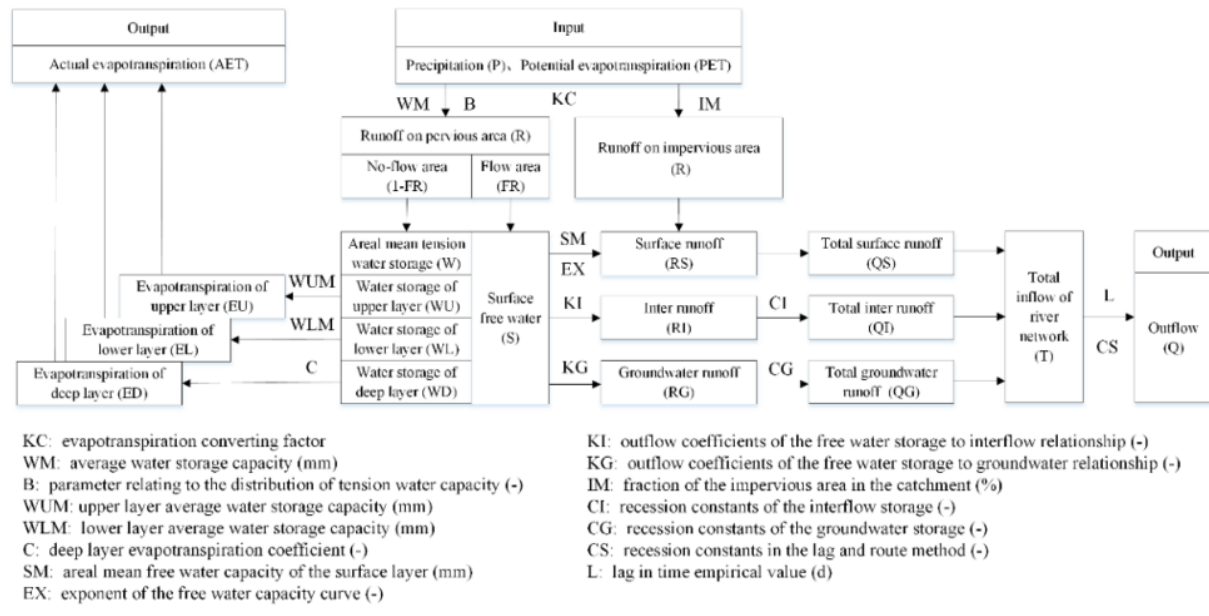

Figure 2. Structure of the XAJ model.

\subsection{Performance Evaluation Indices for SPPs and Streamflow}

Several statistical indices, including correlation coefficient (CC), mean error (ME), relative bias (rBIAS) and root mean square error (RMSE), are adopted for the evaluation of SPPs. Generally, CC reflects the ability of SPP to capture the spatial pattern of precipitation, ME describes the general deviation of SPP estimates from rain gauge observation, rBIAS measures the systematic bias of estimations, and RMSE scales the average error magnitude but gives greater weight to the large errors.

$$
\begin{gathered}
\mathrm{CC}=\frac{\sum_{i=1}^{n}\left(S_{i}-\bar{S}\right)\left(O_{i}-\bar{O}\right)}{\sqrt{\sum_{i=1}^{n}\left(S_{i}-\bar{S}\right)^{2}} \times \sqrt{\sum_{i=1}^{n}\left(O_{i}-\bar{O}\right)^{2}}} \\
\mathrm{ME}=\frac{1}{n} \sum_{i=1}^{n}\left(S_{i}-O_{i}\right) \\
\mathrm{rBIAS}=\frac{\sum_{i=1}^{n}\left(S_{i}-O_{i}\right)}{\sum_{i=1}^{n} O_{i}} \times 100 \% \\
\mathrm{RMSE}=\sqrt{\frac{1}{n} \sum_{i=1}^{n}\left(S_{i}-O_{i}\right)^{2}}
\end{gathered}
$$

where $S_{i}$ is the estimated precipitation of SPP; $O_{i}$ is the observed precipitation of rain gauge; $n$ denotes the number of samples; $\bar{S}$ is the mean value of estimated 
precipitation; and $\bar{O}$ is the mean values of observed precipitation.

In terms of the streamflow evaluation, the Nash-Sutcliffe efficiency [14] widely used in hydrological field is selected, which can be expressed as:

$$
\mathrm{NSE}=1-\frac{\sum_{t=1}^{n}\left(Q_{s i m, t}-Q_{o b s, t}\right)^{2}}{\sum_{t=1}^{n}\left(Q_{o b s, t}-\bar{Q}_{o b s}\right)^{2}}
$$

where $Q_{\text {sim }, t}$ and $Q_{\text {obs }, t}$ are the simulated and observed streamflow for time $t$, respectively; $\bar{Q}_{o b s}$ is the mean value of the observed streamflow. NSE value ranges from $-\propto$ to 1 , and a value of 1 means a perfect match between the simulations and observations.

\subsection{Model Calibration and Validation}

To evaluate the applicability of these SPPs in rainfall-runoff simulation over the Xijaing Basin, the XAJ model was driven by each individual SPP and gauge-based interpolation precipitation data. The simulation is performed from 2010 to 2017, with the period of 2010-2014 for calibration and the period of 2015-2017 for validation. The model calibration is based on SCE-UA algorithm and takes the NSE of the daily streamflow at Wuzhou Station as objective function. It is noted that the calibration procedure is carried out separately for each precipitation product.

\section{Results and Discussion}

\subsection{Performance of SPPs}

Table 1 shows the evaluation statistics for the five SPPs with reference to gauge rain gauge data during 2010-2017. In the capture of spatial distribution characteristics, GSMaP_Gauge performs best with CC value of 0.79; followed by CMORPH CRT and TMPA 3B42V7, each with $\mathrm{CC}$ values of 0.71 and 0.69 , respectively. Then GSMaP_MVK is a litter worse with the CC value of 0.64 compared to PERSIANN-CDR with $\overline{C C}$ value of 0.34 . In terms of the accuracy of quantitative estimates, the $\mathrm{ME}$ and rBIAS values of PERSIANN-CDR are the lowest, each with $0.02 \mathrm{~mm}$ and $0.4 \%$ respectively while RMSE value are the highest of $11.9 \mathrm{~mm}$. And the ME and rBIAS values of TMPA 3B42V7 are a little bigger than PERSIANN-CDR; GSMaP_Gauge's RMSE value is the lowest $7.0 \mathrm{~mm}$ and its ME and rBIAS values, -0.15 and $-4.0 \%$ respectively, are almost the same with those of CMORPH CRT. GSMaP_MVK performs worst in ME and rBIAS.

Table 1. Evaluation statistics for five SPPs with reference to gauge rain gauge data.

\begin{tabular}{llllll}
\hline Indices & TMPA 3B42V7 & CMORPH CRT & PERSIANN-CDR & GSMaP_MVK & GSMaP_Gauge \\
\hline CC & 0.69 & 0.71 & 0.34 & 0.64 & 0.79 \\
ME (mm) & 0.06 & -0.17 & 0.02 & -1.22 & -0.15 \\
rBIAS (\%) & 1.7 & -4.6 & 0.4 & -32.6 & -4.0 \\
RMSE (mm) & 9.2 & 8.6 & 11.9 & 9.1 & 7.0 \\
\hline
\end{tabular}




\subsection{Hydrological Response to SPPs}

Figure 3 shows the observed streamflow and simulated streamflow of XAJ model driven by these five SPPs and gauge-interpolated precipitation. Driven by precipitation interpolation data, XAJ model can achieve a good runoff simulation performance, with NSE value of $75.4 \%$ in calibration period and that of $73.8 \%$ in validation period. The $\mathrm{XAJ}$ model driven by each of SPPs has worse performance in comparison to that driven by gauge-based interpolation precipitation. Among these five SPPs, TMPA 3B42V7, CMORPH CRT and GSMaP_Gauge contribute to similar performance in rainfall-runoff simulation, with NSE values of $70.4 \%-71.2 \%$ in model calibration period and that of $70.0 \%-71.6 \%$ in model validation period, which obviously outperform PERSIANNCDR with NSE values of $59.0 \%$ and $64.2 \%$ in calibration period and validation period, respectively. Due to lowest accuracy in precipitation estimates, the uncorrected SPP, i.e., GSMaP_MVK performs worst in the rainfall-runoff simulation, with NSE values of $51.4 \%$ in calibration period and $56.0 \%$ in validation period.
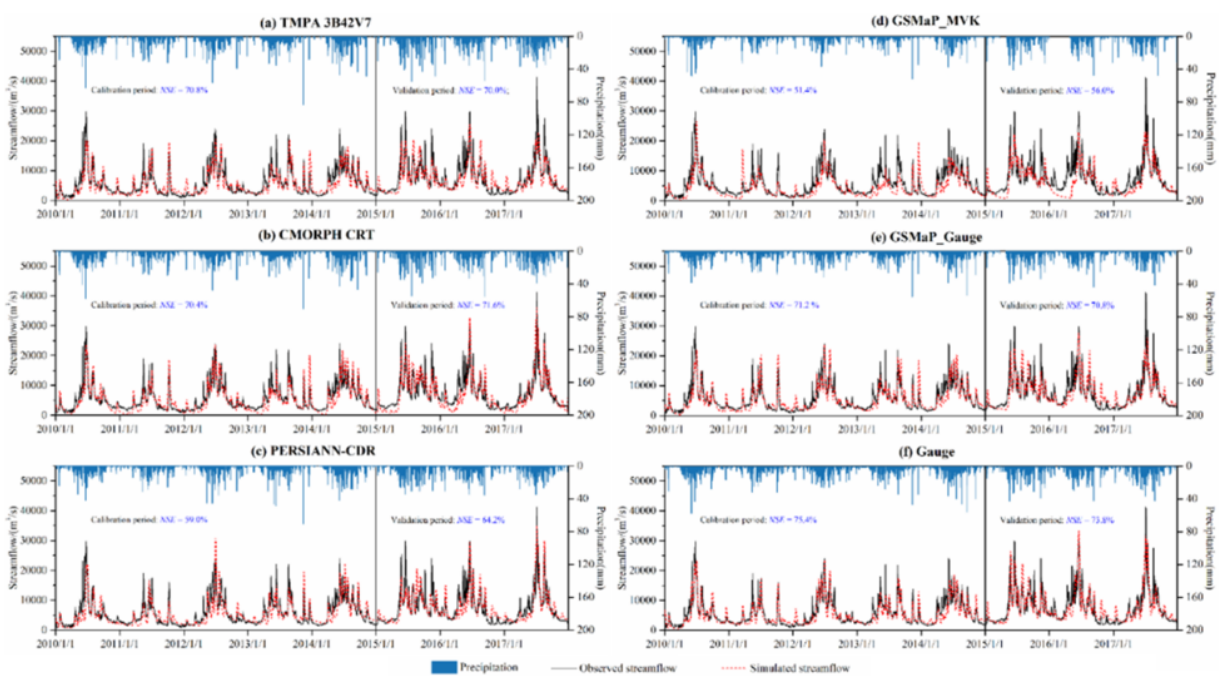

Figure 3. Comparison of observed streamflow and simulated streamflow of XAJ model driven by five SPPS and gauge-interpolated precipitation (at Wuzhou Station).

\section{Conclusions}

This paper evaluates the ability to capture the spatial pattern of precipitation and to quantitatively estimate precipitation for multiple non-real time SPPs, including TMPA 3B42V7, CMORPH CRT, PERSIANN-CDR, GSMaP_MVK and GSMaP_Gauge. Then, driving the XAJ model with each of SPPs and gauge-based interpolation precipitation to simulate the daily streamflow at Wuzhou Station, this paper also evaluates the applicability of SPPs in the rainfall-runoff simulation over Xijiang Basin. The main conclusions are given as follows:

(1) Among the five non-real time SPPs, GSMaP_Gauge performs best in the capture of spatial distribution characteristics and quantitative estimates, then are CORPH CRT and TMPA 3B42 V7, and PERSIANN-CDR has better performance associated with ME 
and rBIAS but performs poorly in $\mathrm{CC}$ and RMSE due to the inconsistent record time with rain gauge observations, in comparison to the uncorrected SPP (GSMaP MVK).

(2) The higher the quality of the data from SPPs, the stronger the hydrological applicability. But due to the fault tolerance ability of hydrological model parameters, the simulation effect of runoff could not be completely dependent on the quality of the data from SPPs. Among the five SPPs, runoff simulation effect driven by CMORPH CRT is best and the NSE value of obtained object function is relatively close to the driving results of precipitation stations' interpolation data. The simulation effect driven by TMPA 3B42V7 is slightly worse than that by CMORPH CRT, but obviously superior than GSMaP_Gauge (with highest accuracy data) and PERSIANN-CDR. And the simulation effect driven by uncorrected product GSMaP_MVK was worst due to its low accuracy.

\section{Acknowledgments}

This research is financially supported jointly by the National Key Research and Development Program of China (2018YFC1508005) and the Indigenous Program of Changjiang Institute of Survey, Planning, Design and Research (CX2019Z13), both of which are greatly appreciated.

\section{References}

[1] Gerstner E M and Heinemann G 2008 Real-time areal precipitation determination from radar by means of statistical objective analysis Journal of Hydrology 352 (3-4) 296-308.

[2] Andréassian V, Perrin C, Michel C, et al. 2001 Impact of imperfect rainfall knowledge on the efficiency and the parameters of watershed models Journal of Hydrology 250 (1-4) 206-223.

[3] Duethmann D, Zimmer J, Gafurov A, et al. 2013 Evaluation of areal precipitation estimates based on downscaled reanalysis and station data by hydrological modelling Hydrology and Earth System Sciences 17 (7) 2415-2434.

[4] Ebert E E, Janowiak J E and Kidd C 2007 Comparison of near-real-time precipitation estimates from satellite observations and numerical models Bulletin of the American Meteorological Society 88 (1) 47-64.

[5] Jia S F, Zhu W B, Lu A F, et al. 2011 A statistical spatial downscaling algorithm of TRMM precipitation based on NDVI and DEM in the Qaidam Basin of China Remote Sensing of Environment 115 (12) 3069-3079.

[6] Huffman G J, Adler R F, Bolvin D T, et al. 2007 The TRMM multisatellite precipitation analysis (TMPA): Quasi-global, multiyear, combined-sensor precipitation estimates at fine scales Journal of Hydrometeorology 8 (1) 38-55.

[7] Joyce R J, Janowiak J E, Arkin P A, et al. 2014 CMORPH: A method that produces global precipitation estimates from passive microwave and infrared data at high spatial and temporal resolution Journal of Hydrometeorology 5 (3) 487-503.

[8] Sorooshian S, AghaKouchak A, Arkin P, Eylander J, et al. 2011 Advanced concepts on remote sensing of precipitation at multiple scales Bull. Amer. Meteor. Soc. 92 1353-1357.

[9] Ushio T, Sasashige K, Kubota T, et al. 2009 A Kalman filter approach to the Global Satellite Mapping of Precipitation (GSMaP) from combined passive microwave and infrared radiometric data J. Meteor. Soc. Japan. 87A 137-151.

[10] Huffman G J, Bolvin D T and Nelkin E J 2015 Integrated multi-satellite retrievals for GPM (IMERG) technical documentation NASA/FSFC Code 61247.

[11] Chen S L, Xiong L H, Ma Q M, et al. 2020 Improving daily spatial precipitation estimates by merging gauge observation with multiple satellite-based precipitation products based on the geographically weighted ridge regression method Journal of Hydrology 589125156.

[12] Allen R G, Pereira L S, Raes D, et al. 1998 Crop evapotranspiration: Guidelines for computing crop water requirements-FAO Irrigation and Drainage Paper 56. FAO, Rome.

[13] Zhao R J 1992 The Xinanjiang model applied in China Journal of Hydrology 135 371-381.

[14] Nash J E and Sutcliffe J V 1970 River flow forecasting through conceptual models' part I-A discussion of principles Journal of Hydrology 10 282-290. 